\title{
Adsorption and disorption characteristics of smectites and aminoglycoside antibiotics
}

\author{
DonghoOn ChunG ${ }^{1}$, WoOHYun ChOI ${ }^{1}$, YUNGOO \\ $\mathrm{SONG}^{1}$, CHANGYUN PARK ${ }^{2 *}$ \\ ${ }^{1}$ Department of Earth System Sciences, Yonsei University, \\ 50 Yonsei-ro, Seodaemun-gu, Seoul, 03722, Korea, \\ Republic of Korea (South); dongh21@yonsei.ac.kr; \\ ${ }^{2}$ Korea Institute of Geoscience and Mineral Resources, \\ Gwahang-ro 124, Daejeon, 305-350, Korea, Republic of \\ Korea (South); (*correspondence: cypark@kigam.re.kr)
}

Clay minerals are widely used to absorbent, carrier, excipient, and ingredient. Especially, as an absorbent and carrier, due to the huge amounts of cation exchange capacity (CEC) among natural materials it has been studied by mineralogists, pharmaceutical chemists, and material scientists. So, as a mineralogist, in this study, I would like to reveal the characteristics of clay minerals-antibiotics hybrid controlled by properties of clay minerals. In this study, the samples are purchased as 2:1 type of clays which supplied by the clay minerals society and kunipia F. And two different bentonite samples from Pohang, gampo in Korea are selected. Antibiotics are selected as clarithromycin (macrolide series), gentamicin, neomycin, and netilmicin (aminoglycoside series). The characteristics of clay minerals were carried out by thermal-gravimetry (TG), scanning electron microscope - energy dispersive Xray spectrometry (SEM-EDS), X-ray diffractometry (XRD), laser particle size analyser, and cation exchange experiment for CEC. To characterize antibiotic-clay mineral hybrids, we analysed the adsorption kinetics, the maximum adsorption amount, the theoretical behaviour of clay interlayer antibiotics and the release of antibiotics in hybrid at room temperature. In selected clay minerals, kunipia F, which was finest grain size, high $\mathrm{Si}, \mathrm{Al}$ contents, and low $\mathrm{Fe}$ contents, was show the highest adsorption capacity. I expect that it is easier to select the suits clay minerals for each usage and to explore the suit clay mineral deposits by this study. 